Brazilian Journal

of Chemical

ISSN 0104-6632

Printed in Brazil

Engineering

www.scielo.br/bjce

Vol. 35, No. 02, pp. 353 - 362, April - June, 2018

dx.doi.org/10.1590/0104-6632.20180352s20160374

(cc) BY

\title{
THE USE OF COMPRESSED
}

\section{FLUIDS TO OBTAIN BIOCOMPOSITES FROM PALM OIL FIBER (ELAEIS SP.)}

\author{
Aline L. P. C. de Oliveira ${ }^{1}$, Antônio Clinton da C. Goes ${ }^{1}$, Priscila S. \\ Almeida $^{1}$, Gustavo R. Borges ${ }^{1, *}$, Elton Franceschi ${ }^{1}$ and Cláudio Dariva ${ }^{1}$ \\ ${ }^{1} \mathrm{PBI} / \mathrm{PEP} / \mathrm{UNIT}$, Nucleo de Estudos em Sistemas Coloidais, NUESC, Universidade \\ Tiradentes, Av. Murilo Dantas 300, Aracaju/SE, Brazil, CEP: 49032-490.
}

(Submitted: June 13, 2016; Revised: January 31, 2017; Accepted: February 15, 2017)

\begin{abstract}
Empty fruit bunch fiber (EFBF) is a lignocellulosic waste generated by the palm oil agribusiness. The amount of EFBF produced is equal to the oil obtained, and it can be used as raw material to obtain biocomposites. The objective of this work is to fragment the EFBF employing pressurized fluids in a semi-continuous system to obtain different biocomposites. For this, pure water and a mixture of water/carbon dioxide were employed as solvent to obtain sugar monomers and a mixture of compressed water/ethanol (1:1 vol.) to obtain crystalline cellulose. The experiments were conducted in the temperature range of 120 to $240{ }^{\circ} \mathrm{C}$, using reaction times between 5 and $15 \mathrm{~min}$ at $60 \mathrm{bar}$, and solvent flow rate of $0.75 \mathrm{~mL} \cdot \mathrm{min}^{-1}$. A maximum of $30.47 \mathrm{mg} \cdot \mathrm{mL}^{-1}$ of xylose was obtained at $210^{\circ} \mathrm{C}$ for $15 \mathrm{~min}$ of reaction with pure water as solvent. The best condition to obtain crystalline cellulose was $240^{\circ} \mathrm{C}$ for 30 minutes of reaction, obtaining $38.2 \%$ of cellulose from palm oil EFBF.
\end{abstract}

Keywords: Palm oil waste, Biocomposites, Pressurized fluids.

\section{INTRODUCTION}

The different effects of the use and depletion of fossil fuels, such as environmental pollution and dependence on petrochemicals, are a matter of concern worldwide. Alternative technologies and sustainable solutions for converting biomass and obtain biocomposites and biofuels are being increasingly designed and developed (Nel e Cooper, 2009; Zakaria et al., 2015).

Lignocellulosic biomass is a heterogeneous polymer composed of carbohydrates and lignin. Its use can be entire or by deconstruction into its constituent polymers: cellulose, hemicellulose and lignin. In the bio-refinery concept, the use of lignocellulosic biomass happens by a different process, optimized and integrated aiming to produce several products, such as carbohydrates, oils, lignin, carotenoids among others. This range of products can also be transformed into fuels and biocomposites with aggregate values (Vaz Jr., 2012; Carvalheiro et al., 2008; Mood et al., 2013; García et al., 2014).

Several vegetable sources can be used to substitute fossil fuels, for example, wastes of the palm oil agro industry. In Brazil, the area planted in 2013 was 122.000 hectares, with a total of 1.34 million tons of harvested bunches and 335.000 tons of oil produced (BRASIL, 2015).

* Corresponding author: gustavorborges01@gmail.com 
The different solid wastes generated, such as leave, mesocarp, the empty fruit bunch fiber (EFBF), and endocarp are mostly used as energy sources in boilers of the extractor plants. However, it is logical to think of different ways to use this waste as a renewable biocomposites/biofuels source. EFBF, the structure supporting the fruits, represents around $20 \%$ of the total weight of the bunch. This amount is equal to the percentage of oil extracted, being a residue of high availability (Chiesa e Gnansounou, 2014).

Among different processes to convert biomass, the most used routes nowadays and the most promising are physical-chemical processes. However, most technologies (acid, alkaline or enzymatic hydrolysis) demand a significant quantity of chemical products and catalysts, as highlighted by Lachos-Perez et al. (2016). As an alternative to these processes, pressurized fluids such as sub/ supercritical water and mixtures of water with ethanol or carbon dioxide (green solvents) have been applied in different biomass conversion processes, obtaining high recovery levels of different bioproducts (Oliveira et al., 2017; Lachos-Perez et al., 2016; Saldaña and Valdivieso-Ramírez, 2015; Relvas et al., 2015; Alvarez et al., 2014).

Another advantage of the pressurized fluids is the possibility to easily manipulate certain characteristic of the solvent such as density, polarity, viscosity and dielectric constant by changing the system temperature and pressure. This characteristic allows control of the solubility and fragmentation power of different compounds aiming to maximize the production of specific phytochemicals from a variety of biomasses; in addition, high yields are achieved without the use of catalyst (Kurnin et al., 2016; Wen et al., 2009; Saldana and Valdivieso-Ramírez, 2015). The fluids to be used must have critical pressure and temperature adequate for the process, good solubility for the solute, be inert and easily separated from the obtained product and have low cost (Toor et al., 2011).

Continuous or semi-continuous processes have been reported in the literature as an alternative to batch ones for obtaining products of interest from biomass, for example, bio-oil (Oliveira et al., 2017), sugars (Lachos-Perez et al., 2016) and phytochemicals such as phenolics and antioxidant (Alvarez et al., 2014). The main advantage of these processes is the possibility to control independently all the process variables. Recently our group proposed a semi-continuous unit for biomass liquefaction that, different from the other processes for hydrothermal liquefaction (HTL), dispenses the use of biomass slurries, since a pure or a mixture of solvents is pumped through a reactor that contains the biomass (Oliveira et al., 2017). A similar apparatus for subcritical water hydrolysis $(\mathrm{SWH})$ was also described by Lachos-Perez et al. (2016).

In this sense, this study has the objective to fragment empty palm oil bunch fiber through pressurized fluid technology to obtain different biocomposites employing the apparatus described previously with a small modification.

\section{EXPERIMENTAL}

Empty fruit bunch fiber (EFBF) from palm oil (variety Dura) was provided by Empresa Baiana de Desenvolvimento Agrário - EBDA. The EFBF was dried in the sun for two days, manually cut, crushed in a slicer, and classified with Tyler series sieves in the range of 32-60 mesh. The raw fiber was stored in glass containers. All the experiments were performed using the same lot of EFBF. The CHN (carbon, hydrogen and nitrogen) content of the EFBF was measured in a CHN analyzer (Perkin-Elmer, model 2400 XP) and the moisture content was determined by titration using the Karl Fischer reagent in an automatic titrator (Methrom, $870 \mathrm{KF}$ titrino plus).

\section{Lignocellulosic characterization}

For lignocellulosic characterization of the empty fiber bunch fiber the methodology developed by National Renewable Energy Laboratory - NREL/TP510-42618 (NREL, 2008) was followed. First, the EFBF water/ethanol soluble portion was removed through Soxhlet extraction. In sequence, the material was hydrolyzed in $72 \%$ sulfuric acid at $30{ }^{\circ} \mathrm{C}$ for 60 min. After this, the hydrolyzed mixture was diluted to $4 \%$ in water, autoclaved at $121{ }^{\circ} \mathrm{C}$ for 1 hour, and filtered in porous baffle crucibles. The solid residual waste was considered to be Klason lignin.

UV-VIS spectrophotometry was used to determine the soluble lignin in the hydrolyzed liquid, at a wavelength of $280 \mathrm{~nm}$. The sugar content was determined through the concentration of cellobiose, glucose, xylose, mannose, galactose and arabinose employing High Performance Liquid Chromatography - HPLC (Shimadzu Prominence, model LC10AD), with a refraction ratio detector (RID-10A) and SPD-M20A of the DAD type (Diode Array Detector) for spectrophotometry in the ultraviolet. Analyses were realized in a Supelcogel $\mathrm{Pb}$ column at $85^{\circ} \mathrm{C}$, preceded by a Supelguard $\mathrm{Pb}$ guard column, eluted with ultrapure water with a constant flow rate of $0.6 \mathrm{~mL} \cdot \mathrm{min}^{-1}$. 
To determine the degradation products hydroxyl-methyl-furfural (HMF) and furfural the same equipment described above was employed with ultraviolet detector and an Aminex Bio-Rad HPX-87H column at $65{ }^{\circ} \mathrm{C}$, equipped with a guard column, eluted with a solution of $\mathrm{H}_{2} \mathrm{SO}_{4}(5 \mu \mathrm{M})$ at a constant flow rate of 0.6 $\mathrm{mL} \cdot \mathrm{min}^{-1}$.

\section{Thermogravimetric analyses (TG)}

The thermal behavior of the empty fiber bunch fiber (EFBF) was studied in a differential thermogravimetric analyzer (Shimadzu, DTG-60H). The samples were heated from room temperature up to $800^{\circ} \mathrm{C}$ at a heating rate of $20{ }^{\circ} \mathrm{C} \cdot \mathrm{min}^{-1}$. High purity nitrogen (99.99\%, White Martins) was used as purge gas (flow rate of $50 \mathrm{~cm}^{3} \cdot \mathrm{min}^{-1}$ ) to provide an inert atmosphere around the sample during analyses. The sample mass lost due to heating (TG) and its first derivative (DTG) were continuously collected with the aid of a specific software.

\section{EFBF Fragmentation}

For the EFBF fragmentation process, a semi-continuous biomass thermoconversion unit (Figure 1) was employed. The main difference of this apparatus to that described previously (Oliveira et al., 2017) is the possibility of operation with pressurized liquid and gas solvents simultaneously employing a HPLC pump (Fischer Scientific, Series III) and a syringe pump (Isco, model 260D) connected with a thermostatic bath kept at $7{ }^{\circ} \mathrm{C}$ to maintain the carbon dioxide $\left(\mathrm{CO}_{2}\right)$ in the liquid state at $100 \mathrm{bar}$, allowing one to calculate the solvent density (0.9374 g.cm ${ }^{-3}$ - NIST, 2017). These pumps move the liquid and gaseous solvent, respectively, in the whole system line. The oven (Jung) can operate at temperatures up to $1000{ }^{\circ} \mathrm{C}$. The reactor is a stainless steel tube (Swagelok), with $30 \mathrm{~cm}$ of length and external diameter of $3 / 8$ ". The reactor outlet has a condenser and a zero volume pressure transducer (NOVUS, model TP-691) connected to an universal indicator used to monitoring the system pressure. A needle valve located at the end of the line is employed for adjustment/control of the system pressure. Two thermocouples, one connected at the inlet and another at the outlet of the reactor, were used to measure the temperature inside the oven.

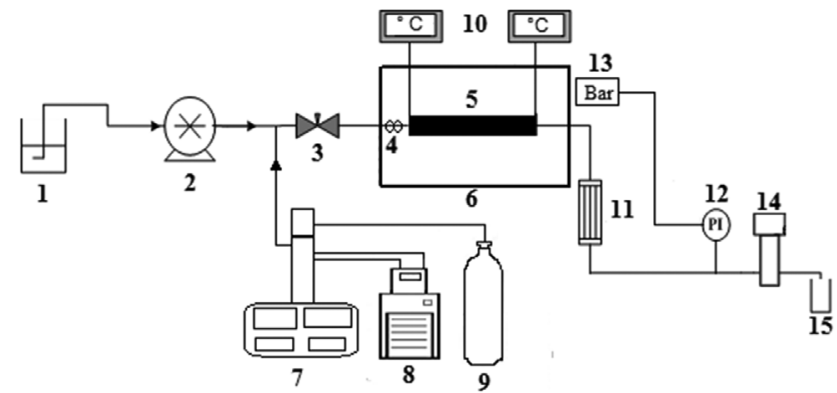

Figure 1: Biomass thermoconversion unit, with capacity to operate with pressurized liquid and/or gaseous solvents in semi-continuous flow. 1- solvent reservoir; 2- isocratic pump; 3- micrometric valve; 4- pre-heater zone; 5reactor; 6- oven; 7- syringe pump; 8 - batch; 9- $\mathrm{CO}_{2}$; 10 - inlet and outlet temperature indicators; 11 - cold zone; 12 - pressure transducer; 13 - pressure indicator; 14- back pressure regulator and 15- sample flask.

At each experimental run the reactor was loaded with about $1 \mathrm{~g}$ of EFBF and connected to the system. Then, the solvent or the mixture of solvents was pumped to fill the line and set at the desired pressure. The oven is turned on with a heating rate of $20^{\circ} \mathrm{C} \cdot \mathrm{min}^{-1}$ up to the programmed temperature. When the working temperature and pressure are reached, the liquid fraction is collected during a defined time (according to Table 1) at constant flow rate $\left(0.75 \mathrm{~mL} \cdot \mathrm{min}^{-1}\right)$. After the fragmentation the oven was shut down and the extract was collected for 5 more minutes to ensure the recuperation of all fragmented products inside the reactor and outlet lines. After this time, the solvent flow was interrupted and the system was depressurized. The biomass (EFBF) remaining in the reactor was removed and dried in an oven at $40{ }^{\circ} \mathrm{C}$ until constant weight. All the experiments were performed in duplicate from where the errors were calculated and presented in the form of an error bar in the graphs. The percentage of consumed/fragmented biomass was calculated by Equation 1.

$\%$ mass consumption $=\frac{(\text { initial mass }(g)-\text { final mass }(g))}{\text { initial mass }(g)} 100$

The fragmentation runs were performed, first, employing pure water as solvent (with a constant flow rate of $0.75 \mathrm{~mL} \cdot \mathrm{min}^{-1}$ and pressure of 60 bar) aiming to extract xylose from EFBF. The experimental conditions adopted for these tests are summarized in Table 1. 
Table 1: Experimental conditions for palm oil EFBF fragmentation employing pure water and water/ethanol (1:1 vol.) as solvent.

\begin{tabular}{ccc}
\hline Run & Temperature $\left({ }^{\circ} \mathbf{C}\right)$ & Time $(\boldsymbol{m i n})$ \\
\hline 1 & 120 & 5 \\
2 & 150 & 5 \\
3 & 180 & 5 \\
4 & 210 & 5 \\
5 & 240 & 5 \\
6 & 120 & 15 \\
7 & 150 & 15 \\
8 & 180 & 15 \\
9 & 210 & 15 \\
10 & 240 & 15 \\
11 & 120 & 30 \\
12 & 150 & 30 \\
13 & 180 & 30 \\
14 & 210 & 30 \\
15 & 240 & 30 \\
\hline
\end{tabular}

For the best condition found in the fragmentation process by pressurized water, a certain amount of carbon dioxide $\left(\mathrm{CO}_{2}\right)$ was added as co-solvent aiming to increase xylose yield by medium acidification. The amount of $\mathrm{CO}_{2}$ present in the water during the experiments was calculated based on the study of Duan and Sun (2003), which shows that, at a pressure of 100 bar, the maximum solubility of $\mathrm{CO}_{2}$ in water is approximately $0.7 \mathrm{~mol}$ of $\mathrm{CO}_{2}$ per $\mathrm{kg}$ of water, in the temperature range studied in this step $\left(180-240^{\circ} \mathrm{C}\right)$. The volumetric ratio of each solvent was calculated considering the density of each one at the pressure of 100 bar for each temperature. To ensure that the maximum solubility of $\mathrm{CO}_{2}$ in water was attained, the $\mathrm{CO}_{2}$ was added with an excess of 1.5 fold, considering a total flow rate of $1.0 \mathrm{~mL} \cdot \mathrm{min}^{-1}$. The values of flow rates calculated for each solvent are shown in Table 2.

Table 2: Solvent flow rate $\left(\mathrm{mL} \cdot \mathrm{min}^{-1}\right)$ for the EFBF fragmentation employing water/ $\mathrm{CO}_{2}$ as solvent.

\begin{tabular}{ccc}
\hline Temp. $\left({ }^{\circ} \mathbf{C}\right)$ & Water & $\mathbf{C O}_{2}$ \\
\hline 180 & 0.75 & 0.25 \\
210 & 0.74 & 0.26 \\
240 & 0.74 & 0.26 \\
\hline
\end{tabular}

In a second set of experiments a mixture of water/ ethanol (1:1 vol.) was employed as fragmentation solvent aiming to obtain cellulose from EFBF. The experimental conditions evaluated were the same presented in Table 1. All the fragmentations were performed in duplicate with a constant flow of $0.75 \mathrm{~mL} \cdot \mathrm{min}^{-1}$ and pressure of 60 bar.

\section{Characterization of the liquid extract obtained from the fragmentation with pressurized water and pressurized water + carbon dioxide}

The composition in sugars and products of degradation of liqueurs obtained from the fragmentation was performed following the methodology described by NREL/TP-510-42623, using the same equipment and chromatographic conditions described previously.

Characterization of the solid products obtained from the fragmentation by pressurized water/ethanol (1:1 vol.) mixture

The solid wastes remaining from the best fragmentation conditions were analyzed by Fourier Transform Infrared Spectroscopy - FT-IR (Agilent Technologies, Model Cary 630 FT-IR). The samples were evaluated in the spectral range of 4000 to $650 \mathrm{~cm}^{-1}$ and each spectrum presented is an average of 16 scans. For X-Ray Diffraction - X-RD analysis a Empyrean diffractometer (PANalytical) with radiation CU-K $\alpha\left(1^{\circ}=\right.$ $1.5406 \AA$ ) was employed. All the data were collected in a continuous way in Bragg-Brentano geometry with a range of $2 \theta$ from $10^{\circ}$ to $50^{\circ}$ according to Hassan et al. (2013) and a step size of $0.01^{\circ}$. Both analyses were compared with the spectrum and the diffractogram of standard cellulose (Sigma Aldrich, U.S - C6288) to identify the best experimental condition to obtain cellulose of greater quality and crystallinity.

\section{RESULTS AND DISCUSSION}

The lignocellulosic characterization of the empty fiber bunch fiber (EFBF) performed according to NREL/TP-510-42618 and the elemental composition are presented at Table 3 . The results of lignocellulosic characterization suggested that the palm oil EFBF employed in this work is similar to that reported by Hassan et al. (2013) and Chiesa and Gnansounou (2014), with a total content of holocellulose (cellulose + hemicellulose) and lignin close to $50 \%$ and $25 \%$, respectively. The elemental composition analysis of EFBF indicates high content of carbon and oxygen in the biomass, and the values are in agreement with those reported in the literature (Chang, 2014). 
Table 3: Lignocellulosic characterization and elemental composition of the empty fiber bunch fiber (EFBF).

\begin{tabular}{lc}
\hline & Content $(\mathbf{\%})$ \\
\hline Cellulose & 33.9 \\
Hemicellulose & 15.0 \\
Lignin & 28.1 \\
Moisture & 7.6 \\
Extractive & 15.3 \\
Ashes & 7.6 \\
Carbon & 40.5 \\
Hydrogen & 5.9 \\
Nitrogen & 0.0 \\
Oxygen* & 53.6
\end{tabular}

*Calculated by diference.

\section{Thermogravimetric analyses (TG)}

The thermogravimetric analyses performed at temperatures up to $800{ }^{\circ} \mathrm{C}$ indicate a mass loss of palm oil EFBF of approximately $70 \%$, as can be seen in Figure 2. Initially, a loss around $10 \%$ was observed in the temperature range from 100 to $225^{\circ} \mathrm{C}$, attributed to the water and smaller chain compounds present in the sample. The most significant mass loss was observed between 225 and $340{ }^{\circ} \mathrm{C}$, as evidenced by the DTG curve, being approximately $35 \%$. This loss can be related to holocellulose degradation (Lin et al., 2015). However, a bigger mass loss was expected in this temperature range, because the holocellulose content in the sample is close to $50 \%$, but it should be emphasized that other factors, such as cellulose crystallinity, may influence the degradation process (Hassan et al., 2013). Above $340^{\circ} \mathrm{C}$ up to the final temperature the mass loss happens slowly. In this temperature range the loss was close to $25 \%$ of the total mass, and can be attributed to the degradation of the remaining holocellulose and lignin (Lin et al., 2015). The high ash content $(7.6 \%)$, allied to charcoal formation, contributes to a lesser total mass loss.

\section{Fragmentation of palm oil EFBF by pressurized water}

The fragmentation profile of palm oil EFBF by pressurized water can be seen in Figure 3. As one can note, the error bars that indicate the reproducibility of the apparatus are smaller than the symbols for most of the conditions presented in Figures 3 and 4. Time variation from 5 to $30 \mathrm{~min}$ at temperatures of 120 and 150 ${ }^{\circ} \mathrm{C}$ does not causes a significant difference on the extracted mass. At this condition the mass consumption was close to $15 \%$, being in accordance with reported values of extractive compounds determined in this work by the NREL/TP-510-42618 test. When the fragmentation temperature was $180^{\circ} \mathrm{C}$ the same behavior was observed at 5 and 15 minutes. Similar yield was observed by Chiesa et al. (2014) performing an acid treatment of palm oil EFBF using sulfuric acid (0.05 vol $\%)$ at $140{ }^{\circ} \mathrm{C}$ for 10.5 minutes, the mass extracted being close to $15 \%$. After 30 minutes of fragmentation at $180{ }^{\circ} \mathrm{C}$ approximately $33 \%$ of the EFBF loaded in the reactor was fragmented.

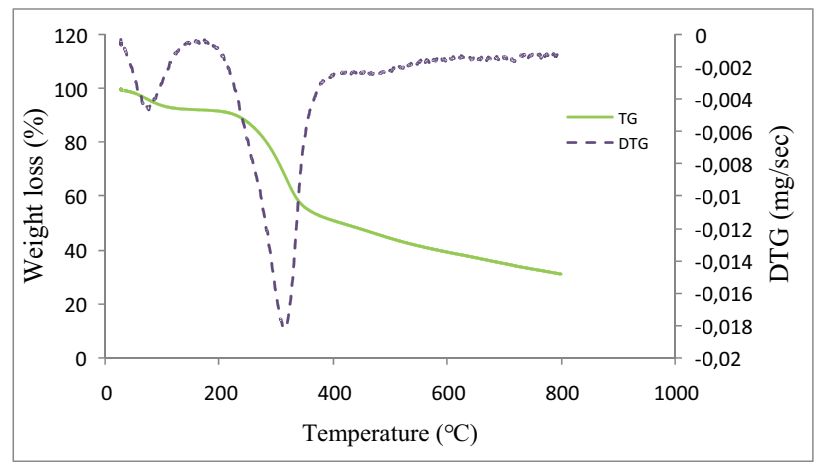

Figure 2: Palm oil EFBF TG and DTG curve.

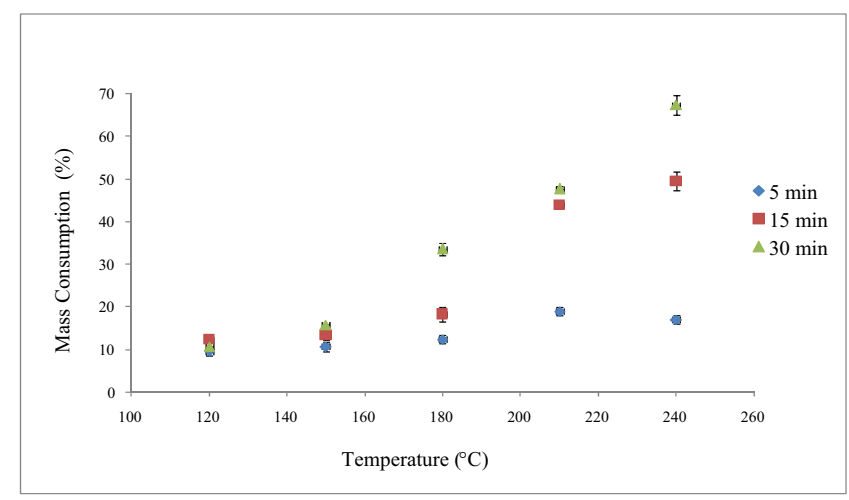

Figure 3: Fragmentation profile of palm oil EFBF using pressurized water as solvent at 60 bar.

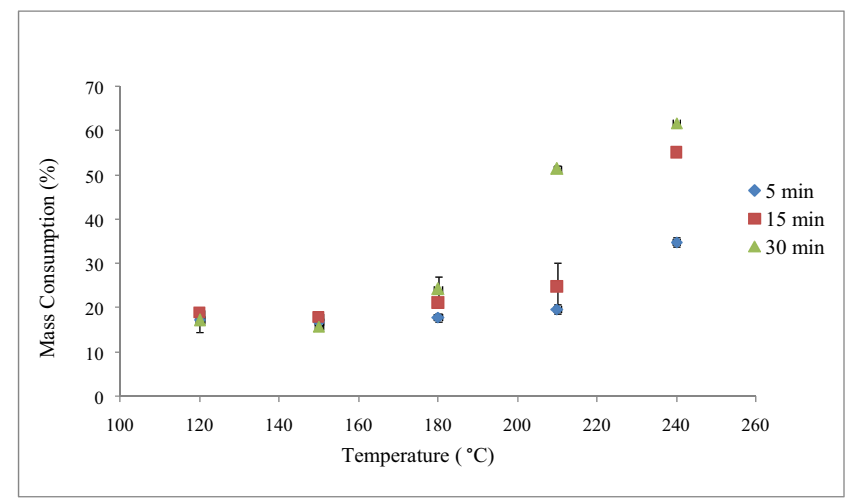

Figure 4: Palm oil EFBF fragmentation profile using pressurized water/ ethanol mixture (1:1 vol.) at 60 bar. 
At $210^{\circ} \mathrm{C}$ one can observe a drastic increment in the EFBF consumption from 5 to 15 min of fragmentation where the mass consumption increases from $19 \%$ to $44 \%$. However, this percentage was only raised $3.7 \%$ in 30 minutes of extraction, reaching a maximum of $47.6 \%$ of mass consumption.

The highest fragmentation was achieved at $240{ }^{\circ} \mathrm{C}$ with 30 minutes of reaction, reaching a maximum of consumed mass of $67.3 \%$. Chiesa et al. (2014) obtained similar results $(66.5 \%$ of mass consumption) at $210{ }^{\circ} \mathrm{C}$ in 20 minutes employing an acid treatment (1.02\%vol of sulfuric acid).

The mass consumption with $15 \mathrm{~min}$ at $240{ }^{\circ} \mathrm{C}$ $(49.5 \%)$ is similar to those obtained with $30 \mathrm{~min}$ of extraction at $210^{\circ} \mathrm{C}$. In 5 minutes of extraction at 240 ${ }^{\circ} \mathrm{C}$ there was no EFBF fragmentation, only extraction of soluble compounds.

As one can note in Figure 3, the best conditions for palm oil EFBF fragmentation using pure water as solvent are at temperatures above $180{ }^{\circ} \mathrm{C}$ with fragmentation/reaction time above $15 \mathrm{~min}$. So, for these conditions, the effect of carbon dioxide $\left(\mathrm{CO}_{2}\right)$ on the mass consumption was evaluated. The $\mathrm{CO}_{2} /$ water ratios employed are summarized in Table 2 . Table 3 present a comparison between the experimental runs with and without $\mathrm{CO}_{2}$. The addition of $\mathrm{CO}_{2}$ in the fragmentation process represented a small gain in fragmentation yield of the EFBF only at $180^{\circ} \mathrm{C}$ with $30 \mathrm{~min}$ of reaction. On the other hand, at $210^{\circ} \mathrm{C}$ with 15 min of fragmentation the mass consumption decreased in the presence of $\mathrm{CO}_{2}$. For all the other experimental conditions the injection of $\mathrm{CO}_{2}$ did not significantly change the mass consumption.

The chemical characterization regarding the content of sugars monomers and degradation products presents in the liqueurs obtained from fragmentation of palm oil EFBF by pure water is presented in Table 5. For this process the product of interest is xylose. The low glucose value is indicative that the cellulose was preserved.

Table 4: Consumed mass percentage of EFBF fragmentation using $\mathrm{H}_{2} \mathrm{O}$ and $\mathrm{H}_{2} \mathrm{O} / \mathrm{CO}_{2}$ for the respective experimental conditions.

\begin{tabular}{ccccc}
\hline & \multicolumn{4}{c}{ Reaction time (minutes) } \\
& \multicolumn{2}{c}{$\mathbf{1 5}$} & \multicolumn{2}{c}{$\mathbf{3 0}$} \\
\hline Temp $\left({ }^{\circ} \mathbf{C}\right)$ & $\mathbf{H}_{2} \mathbf{O}$ & $\mathbf{H}_{2} \mathbf{O} / \mathbf{C O}_{2}$ & $\mathbf{H}_{2} \mathbf{O}$ & $\mathbf{H}_{2} \mathbf{O} / \mathbf{C O}_{2}$ \\
180 & - & - & $33.6 \pm 1.4$ & $39.0 \pm 0.3$ \\
210 & $44.0 \pm 0.7$ & $36.7 \pm 1.5$ & $47.6 \pm 0.6$ & $49.0 \pm 4.2$ \\
240 & $49.5 \pm 2.2$ & $52.1 \pm 5.3$ & $67.3 \pm 2.4$ & $62.5 \pm 2.7$ \\
\hline
\end{tabular}

Table 5: Sugar monomers and degradation product concentrations (mg. $\left.\mathrm{mL}^{-1}\right)$ from liqueurs obtained from EFBF fragmentation using pressurized water at distinct experimental conditions.

\begin{tabular}{cccccccc}
\hline Run & $\begin{array}{c}\text { Experimental Conditions } \\
\text { Temperature } \\
\left({ }^{\circ} \mathbf{C}\right)\end{array}$ & Time (min) & Glucose & Xylose & Arabinose & HMF & Furfural \\
\hline 1 & 120 & 5 & 0.39 & 0.22 & 0.28 & 0.01 & 0.01 \\
2 & 120 & 15 & 0.31 & 0.17 & 0.15 & 0.02 & 0.02 \\
3 & 120 & 30 & 0.23 & 0.15 & 0.07 & 0.01 & 0.01 \\
4 & 150 & 5 & 0.57 & 0.27 & 0.30 & 0.02 & 0.02 \\
5 & 150 & 15 & 0.45 & 0.28 & 0.32 & 0.02 & 0.03 \\
6 & 150 & 30 & 0.39 & 0.50 & 0.44 & 0.02 & 0.02 \\
7 & 180 & 5 & 0.46 & 0.28 & 0.18 & 0.05 & 0.05 \\
8 & 180 & 15 & 0.74 & 2.14 & 1.38 & 0.03 & 0.03 \\
9 & 180 & 30 & 0.89 & 12.81 & 1.58 & 0.04 & 0.04 \\
10 & 210 & 5 & 1.24 & 6.66 & 1.60 & 0.03 & 0.03 \\
11 & 210 & 15 & 2.08 & 30.47 & 2.23 & 0.08 & 0.09 \\
12 & 210 & 30 & 1.23 & 21.83 & 1.37 & 0.06 & 0.06 \\
13 & 240 & 5 & 0.42 & 0.36 & 0.18 & 3.20 & 3.95 \\
14 & 240 & 15 & 0.54 & 5.84 & 0.38 & 5.87 & 3.94 \\
15 & 240 & 30 & 0.44 & 3.85 & 0.28 & 6.38 & 3.93 \\
\hline
\end{tabular}


As can be seen, the concentration of sugar monomers and degradation products in the liqueurs is low for experiments performed at the lowest temperatures $120-150{ }^{\circ} \mathrm{C}$ (runs $1-6$ ). At $180^{\circ} \mathrm{C}$ and fragmentation time above $15 \mathrm{~min}$ the sugars concentration in the liqueur increases considerably, indicating the beginning of fractionation.

The liquor with highest concentration in sugar monomers was obtained at $210{ }^{\circ} \mathrm{C} / 15$ minutes. As one can note, xylose was the sugar most formed (30.47 mg. $\mathrm{mL}^{-1}$ ) in the palm oil EFBF fragmentation employing pressurized water as solvent. The concentration of glucose and arabinose remains always below 2.08 and $2.23 \mathrm{mg} . \mathrm{mL}^{-1}$, respectively, and the presence of degradation products in the liquor is very low $\left(<0.09 \mathrm{mg} \cdot \mathrm{mL}^{-1}\right)$. The high content of xylose in the liqueurs can be attributed to two main factors: first, palm oil EFBF is composed of $24 \%$ xylene, a polymer constituted of xylose, which composes hemicellulose (Wyman, 1994) and, second, the temperature and reaction time evaluated were not enough to break up the cellulose due to its high crystallinity. Hassan et al. (2013) claim that the severity of the treatment should be adequately controlled to ensure the maximum recuperation of sugars of interest. This shows that the palm oil EFBF fragmentation with pressurized water is a very selective process to obtain xylose.

When the reaction time and temperature are increased (run 12-15) the concentration of sugar monomers formed decreased. This fact can be related with sugars degradation, since the concentration of degradation products increased, mainly at $240{ }^{\circ} \mathrm{C}$. According to previous work (Lachos-Perez et al., 2016), high temperatures promote organic acid formation and, consequently, the $\mathrm{pH}$ of the hydrolysate decreases, leading to xylose degradation and an increase in hydroxyl methyl-furfural (HMF) concentration.

However, in this work the formation of degradation products was not proportional to sugars degradation. This fact can be related to the formation of intermediate compounds from the sugar breakdowns, which were not quantified/identified. The addition of $\mathrm{CO}_{2}$ to the water did not cause alterations in chemical composition.

\section{Fragmentation of EFBF by pressurized water/etha- nol mixture}

The main objective in this section is to obtain cellulose with high purity from palm oil EFBF. For this, a pressurized mixture of water/ethanol (1:1 vol.) was employed as solvent to remove hemicellulose and lignin from EFBF. In this sense, cellulose is the solid portion of EFBF that remains in the reactor after the fragmentation. The aqueous phase (liquor) obtained in this section was not characterized.

Figure 4 shows the palm oil EFBF fragmentation profile employing pressurized water/ethanol mixture at different temperatures and reaction times at 60 bar. The results showed similar behavior to those observed in the fragmentation with pure water, where temperature variation from 120 to $180{ }^{\circ} \mathrm{C}$, using the mixture water/ethanol as solvent, had a small effect on the EFBF fragmentation. In this temperature range the percentage of mass consumption was around $18 \%$, and can be attributed to the EFBF soluble portion.

When the temperature increased to $210^{\circ} \mathrm{C}$ with 30 minutes of reaction time, the mass consumption increased twice compared to the reaction time of $15 \mathrm{~min}$ at the same temperature, reaching a value close to $50 \%$. The maximum consumption (61.7\%) was obtained at the highest temperature and reaction time $\left(240{ }^{\circ} \mathrm{C} / 30\right.$ min), and was close to the best condition obtained with pure water as solvent $(67.3 \%)$ for the same experimental conditions.

The solid remaining in the reactor after the fragmentation/extraction process in the best experimental conditions $\left(210{ }^{\circ} \mathrm{C} / 30 \mathrm{~min}\right.$ and $\left.240{ }^{\circ} \mathrm{C} / 5 / 15 / 30 \mathrm{~min}\right)$ was analyzed by FT-IR and X-RD to check whether the remaining solid is in fact cellulose and to determine the quality and crystallization of the product obtained. All the samples were compared to standard cellulose.

Figure 5 presents a set of FT-IR spectra collected from the different samples compared with standard cellulose. Various absorption bands can be empirically assigned to structural groups of cellulose based on the results obtained from standard cellulose. All samples present these characteristic bands, so one can confirm that the solid obtained from palm oil EFBF after the treatment with pressurized water/ethanol mixture is composed mainly of cellulose.

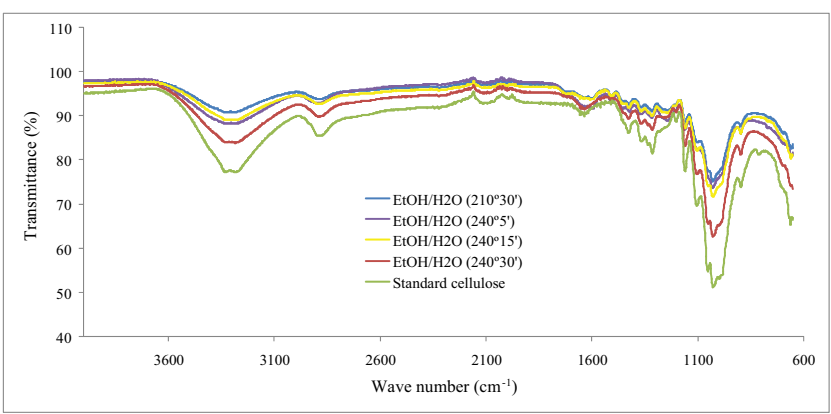

Figure 5: FT-IR spectra from solid wastes of the palm oil EFBF obtained after the treatment with water/ethanol mixture $(1: 1$ vol.) at different experimental conditions and standard cellulose. 
The sample with highest similarity with standard cellulose was obtained at $240{ }^{\circ} \mathrm{C}$ for $30 \mathrm{~min}$ of reaction. Considering that all remaining solid in the reactor is composed of cellulose, the yield obtained for this experimental condition, as a function of the initial biomass and the mass consumed in the fragmentation process, was approximately $38.2 \%$ of cellulose. The result is slightly larger than that reported in the lignocellulosic characterization in Table 3 (33.9\%). It should be emphasized that the cellulose obtained in this work was not submitted to any purification process after the fragmentation step. Thus, some fragments of other compounds that were not isolated from the reactor can be present at the cellulose sample. These fragments can also lead to a displacement of the spectral baseline due to the rise of the transmittance value.

Analyzing the X-RD diffractograms presented in Figure 6 , it is possible to see the characteristic peaks of cellulose at $15^{\circ}, 22^{\circ}$ and $35^{\circ} 2 \theta$ in all the samples obtained under different experimental conditions. These peaks correspond to crystallographic planes (101), (002) and (040), respectively, and are intrinsic of lignocellulosic fibers (Guimarães et al., 2010). The most pronounced peak (close to $26^{\circ} 2 \theta$ ) for the cellulose samples obtained in this work correspond to silicon dioxide, found typically in wood surfaces (Yoon and Kin, 2008).

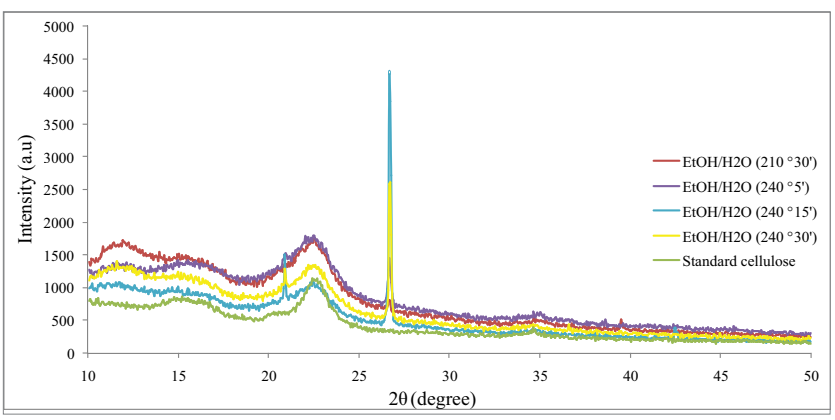

Figure 6: Palm oil EFBF X-RD diffratograms after fragmentation with water/ethanol mixture (1:1 vol.) at different experimental conditions and standard cellulose.

One can note that the intensity of the cellulose samples obtained were above that of the standard cellulose, indicating a higher crystallization index. However, the cellulose obtained at $240{ }^{\circ} \mathrm{C}$ and $30 \mathrm{~min}$ of reaction, has a crystallinity lower than the others obtained at temperatures of $210{ }^{\circ} \mathrm{C}$ and $240{ }^{\circ} \mathrm{C}$ with $5 \mathrm{~min}$ of reaction time, which has intensities above 1500 (a.u), still, this cellulose has an intensity higher than the standard one.
According to Ass et al. (2006), the cellulose obtained from palm oil EFBF is type I, displaying a peak at $22^{\circ} \leq 2 \theta \leq 23^{\circ}$, referring to the crystalline fraction and at $18^{\circ} \leq 2 \theta \leq 19^{\circ}$, regarding the amorphous fraction, whereas type II cellulose presents a peak at $18^{\circ} \leq 2 \theta$ $\leq 22^{\circ}$ for the crystalline region and $13^{\circ} \leq 2 \theta \leq 15^{\circ}$ for the amorphous region.

\section{CONCLUSIONS}

The fragmentation of palm oil EFBF with pressurized water is shown to be an efficient method to obtain xylose. The addition of $\mathrm{CO}_{2}$ to this process did not represent gains to the fragmentation or sugars yield under the conditions studied here. The cellulose obtained after EFBF fragmentation with a water/ethanol mixture (1:1 vol.) was similar to the standard cellulose in terms of purity and crystallinity.

\section{ACKNOWLEDGMENT}

The authors thank to the Tiradentes University, ITP, CAPES, CNPq and FAPITEC/SE for the scholarships and financial support.

\section{REFERENCES}

Alvarez, V. H.; Cahyadi, J.; Xu, D.; Saldaña, M. D. A., Optimization of phytochemicals production from potato peel using subcritical water: Experimental and dynamic modeling. J. of Supercritical Fluids. 90, 8-17 (2014).

Ass, B.A. P.; Belgacem, M. N.; Frollini, E., Mercerized linters cellulose: characterization and acetylation in N,Ndimethylacetamide/lithium chloride. Carbohydr. Polym. 63, 19-29 (2006).

Brasil. Ministério da Agricultura. Pecuária e Abastecimento. Anuário estatístico da agroenergia 2014: statistical yearbook of agrienergy 2014 / MinistériodaAgricultura. PecuáriaeAbastecimento. Secretaria de Produção e Agroenergia. Bilíngue. Brasília: MAPA/ACS. 2015. 205 p.

Carvalheiro. F.; Duarte. L. C.; Gírio. F. M., Hemicellulose biorefineries: a review on biomass pretreatments. J. of Scientific \& Industrial Research. 67, 849-864 (2008).

Chang, S. H., An overview of empty fruit bunch from oil palm as feedstock for bio-oil production. Biomass and Bioenergy. 62, 174-181 (2014). 
Chiesa. S.; Gnansounou. E., Use of Empty Fruit Bunches from the Oil Palm for bioethanol production: A thorough comparison between dilute acid and dilute alkali pretreatment. Bioresource Technology. 159, 355-364 (2014).

García. A.; Alriols. M.; G.; Labidi. J., Evaluation of different lignocellulosic raw materials as potential alternative feedstocks in biorefinery processes. Industrial Crops and Products. 53, 102-110 (2014).

Guimarães, J. L. Wypych, F.; Saul, C. K.; Ramos, L.P.; Satyanarayana, K.G., Studies of the processing and characterization of corn starch and its composites with banana and sugarcane fibers from Brazil. Carbohydratre Polymers. 80, 130- 138 (2010).

Hassan. O.; Ling. T. P.; Maskat. M. Y.; Md. Illias. R.; Badri. K.; Jahim. J.; Mahadi. N. M., Optimization of pretreatments for the hydrolysis of oil palm empty fruit bunch fiber (EFBF) using enzyme mixtures. Biomass and Bioenergy. 56, 137-146 (2013).

Kurnin, N.A.A.; Ismail, M. H. S.; Yoshida, H.; Izhar, S., Recovery of Palm Oil and Valuable Material from Oil Palm Empty Fruit Bunch by Sub-critical Water. Journal of Oleo Science. 65, 283-289 (2016).

Lachos-Perez, D.; Martinez-Jimenez, F.; Rezende, C.A.; Tompsett, G.; Timko, M.; Forster-Carneiro, T., Subcritical water hydrolysis of sugarcane bagasse: An approach on solid residues characterization. J. of Supercritical Fluids 108, 69-78 (2016).

Lin, Y.; Ma, X.; Ning, X.; Yu, Z., TGA-FTIR analysis of co-combustion characteristics of paper sludge and oil-palm solid wastes. Energy Conversion and Management 89, 727-734 (2015).

Mood. S. H.; Golfeshan. A. H.; Tabatabaei. M.; Jouzani. G. S.; Najafi. G. H.; Gholami. M.; Ardjmand. M., Lignocellulosic biomass to bioethanol. a comprehensive review with a focus on pretreatment. Renewable and Sustainable Energy Reviews. 27, 77-93 (2013).

Nel. W. P.; Cooper. C. J., Implications of fossil fuel constraints on economic growth and global warming. Energy Policy. 37, 166-180 (2009).

NIST Chemistry WebBook, National Institute of
Standards and Technology. Available in: http:// webbook.nist.gov/cgi/, Accessed in: January 19, 2017.

NREL - National Renewable Energy Laboratory. Determination of Sugars, Byproducts, and Degradation Products in Liquid Fraction Process Samples. NREL/TP-510-42623 (2008).

Oliveira, A.L.P.C.; Almeida, P.S.; Campos, M.C.V.; Franceschi, E.; Dariva, C.; Borges, G.R., Thermoliquefaction of Palm Oil Fiber (Elaeis sp.) Using Supercritical Ethanol. Bioresource Technology, 230, 1-7 (2017).

Relvas, F. M.; Morais, A. R. C.; Bogel-Lukasik, $\mathrm{R}$. Kinetic modeling of hemicellulose-derived biomass hydrolysis under high pressure $\mathrm{CO}_{2}-\mathrm{H}_{2} \mathrm{O}$ mixture technology. J. of Supercritical Fluids. 99, 95-102 (2015).

Saldaña. M. D. A.; Valdivieso-Ramírez. C. S., Pressurized fluid systems: Phytochemical production from biomass. J. of Supercritical Fluids. 96, 228-244 (2015).

Toor, S. S.; Rosendahl, L.; Rudolf, A., Hydrothermal liquefaction of biomass: A review of subcritical water technologies. Energy. 36, 2328-2342 (2011).

Vaz Jr. S., O potencial dos co-produtos e dos resíduos da biomassa na química renovável. Informativo CRQ-IV. 118, 12-13 (2012).

Wen, D.; Jiang, H.; Zhang, K., Supercritical fluids technology for clean biofuel production, Progress in Natural Science. 19, 273 284 (2009).

Wyman. C. E., Ethanol from lignocellulosic biomass: Technology. economics and opportunities. Bioresource Technology. 50, 3-16 (1994).

Yoon, C. J.; Kim, K. W., Anatomical descriptions of silicified woods from Madagascar and Indonesia by scanning electron microscopy. Micron. 39, 825831 (2008).

Zakaria. M. R.; Norrrahim. M. N. F.; Hirata. S.; Hassan. M. A., Hydrothermal and wet disk milling pretreatment for high conversion of biosugars from oil palm mesocarp fiber. Bioresource Technology. 181, 263-269 (2015). 
